\title{
IMAGENS DA GUERRA: DO HORROR À SEDUÇÃO
}

\section{Discurso da mídia transforma guerra em espetáculo sedutor: a tecnologia fascina o espectador, distanciando-o da história e da realidade}

Vivemos um século marcado pelas guerras. Elas começaram pelas duas de caráter mundial, depois aquelas que tiveram como palco a Coréia, o Vietnã, o Iraque, o Irã e diversos países africanos, com suas lutas civis, incluindo aquelas a que assistimos pela televisão, hoje, trazendo, quase que simultaneamente, as imagens das perdas humanas.

As guerras trouxeram e trazem perdas materiais, e as do século $\mathrm{XX}$, em proporção e quantidade maior do que em outros momentos da História. Os conflitos foram garantidos pelo desenvolvimento de uma tecnologia bélica marcada pela precisão dos alvos, pelo distanciamento espacial dos combatentes e pela banalização da vida, transformando-a em números estatísticos ${ }^{1}$.

Cada vez mais a guerra moderna, com suas invenções, afastou os lados beligerantes, substituindo as trincheiras pelos acertos da máquina, das bombas, pelos ataques aéreos que tornam as cidades - a distância - meros alvos sem vida, como num jogo.

Mas talvez a novidade maior de nosso século, especialmente da metade mais recente, tenha sido não apenas o distanciamento das vítimas e algozes pela técnica, mas a aproximação e a democratização - também pela tecnologia - dos espectadores da guerra. Envolvem-se nela direta ou indiretamen- te os cidadãos numa mobilização da atenção mundial para os acontecimentos, transformando a vida das pessoas, seu cotidiano, suas conversas familiares e escolares.

A maior responsável por essa democratização, sem dúvida, foi a televisão, desde que apresentou ao mundo, pela primeira vez, a Guerra do Vietnã, emocionando e seduzindo em alguns momentos a favor e em outros (com as cenas dos milhares de mortos) contra a guerra milhões de pessoas, principalmente os próprios norte-americanos.

A partir da década de 70 , portanto, as pessoas puderam ter acesso a imagens vivas dos combates, criando a impressão de simultaneidade, encurtando o tempo e a distância, e ampliando as emoções, como se cada espectador pudesse estar in loco nos conflitos.

$\mathrm{O}$ culto à tecnologia e à velocidade (próprios da guerra) expandiu-se no cotidiano do século XX, tornando os fatos bélicos observáveis, cabendo a todos o direito de julgar, opinar e interferir (muitas vezes de forma virtual) em relação aos destinos envolvi$\operatorname{dos}^{2}$. É essa sensação que podemos observar

\section{A AUTORA}

Marta Gouveia de Oliveira Rovai

Professora do Ensino Médio nas redes pública e privada de São Paulo. 
muitas vezes, por exemplo, entre os nossos alunos (e não só entre eles), quando discutem, superficialmente, e se posicionam diante da guerra escolhida, no momento, pelos meios de comunicação, em meio a tantas que se ignoram: a Guerra de Kosovo.

\section{ESPETÁCULO VISTO NA ESCOLA}

Como professora de História no ensino médio, das redes pública e particular, procurei utilizar essa guerra para discutir dois pontos com os alunos: a guerra como marca do século XX e o papel dos meios de comunicação como construtores de imagens sobre ela.

Os meios de comunicação utilizados foram vários, mas deu-se maior valor à televisão, por ser o mais utilizado pelos alunos. A pesquisa e as observações ainda estão em curso, mas os comentários que vão surgindo durante as discussões levantaram angústias que, acredito, devem ser compartilhadas e repensadas por nós, professores que trabalhamos com os meios de comunicação na escola.

A maioria dos alunos, mesmo antes de procurar compreender o processo e a dinâmica histórica de um conflito como o de Kosovo, toma posição baseada na informação disponível apenas nos meios de comunicação. Não se trata aqui, é óbvio, de desprezar o importante papel desses meios no esclarecimento dos fatos, mas sim de chamar a atenção para a forma como eles têm sido recebidos pelos nossos educandos ou até mesmo por nós, professores, supervalorizando-os, muitas vezes, em detrimento de um conhecimento mais amplo e complexo, acumulado pelo tempo.
A televisão tem, nesse sentido, um papel cada vez maior na cobertura dos conflitos, trazendo para dentro dos lares (e indiretamente das escolas, pois os alunos trazem para a sala de aula) as informações e as imagens observadas e recebidas, na maioria das vezes, como frutos da imparcialidade e da neutralidade da câmera que as captou. Esse interesse pela guerra nos últimos anos tem sido estimulado pela grande quantidade de filmes no cinema que retratam diferentes guerras no mundo como um espetáculo hollywoodiano (Linha Vermelha e $O$ resgate do soldado Ryan podem ser citados entre os mais recentes).

$\mathrm{O}$ impacto visual de cenas apresentadas rapidamente, numa sucessão de imagens vindas de países distantes, mostram o planeta como um grande palco unificado, associado a um discurso aparentemente objetivo, neutro, distanciado pela câmera e pelos repórteres (considerados, muitas vezes, por nossos alunos como "meros apresentadores de notícias", transmissores da realidade пиа $e$ crua da guerra). Os meios de comunicação e aí não apenas a televisão - parecem ganhar o aval de discurso competente ${ }^{3}$ para poder dizer, mostrar e direcionar a apresentação dos acontecimentos.

A dinâmica das imagens televisivas é muito rápida, impedindo uma reflexão mais apurada e demorada sobre os acontecimentos e imagens. Ela suscita respostas imediatas, emotivas, que não esperam nem preparam o telespectador para uma análise muito crítica, mas, ao contrário, apressada, oculta todo o preparo, seleção e construção da narração e das imagens que aparecem como notícia.

\footnotetext{
2. Segundo o urbanista e filósofo Paul Virílio, a velocidade é uma das marcas da guerra e marca o cotidiano "civil" da humanidade, produzindo uma "cultura da guerra": a moda de roupas e sapatos militarizados, as vitrinas das lojas que expõem pedaços de asfalto e pedras, forjando um cenário de guerra, para vender mais e seduzir o consumidor. Poderíamos lembrar, ainda, a incorporação da própria linguagem de guerra em nosso cotidiano: os termos "combate esportivo", "batalha eleitoral", "bombardeio de perguntas", a "prova de fogo" ou, na própria escola, "estratégias de ensino".

3. Para usar uma expressão de Marilena Chauí, em relação ao discurso que, munido da ciência ou da técnica, ganha caráter de neutralidade e competência para falar a verdade, produzi-la contra a ideologia ou as falsidades discursivas.
} 


\section{CONTRA A HISTÓRIA, O PRESENTISMO}

Como afirma o historiador Eric Hobbsbawn, nossa sociedade é tomada por um certo presentismo que passa a buscar nas imagens fragmentadas e repetitivas a explicação para os problemas e, no caso, para a própria Guerra de Kosovo, pedindo reações e respostas emotivas e imediatas. Assim, diante da falta de compreensão dos motivos histórico do conflito, é comum ouvirmos nossos alunos dizerem: "Vamos jogar uma bomba lá e explodi-los", como se o que sustentasse aquela relação conflituosa fosse a irracionalidade, a loucura ou simplesmente a vontade de fazer uma guerra, sem explicação. E nós, na incapacidade de entendê-la (pois não cabe a nós, racionais e democráticos, essa missão), estaríamos autorizados a destruí-los, em nome de se evitar o "caos do outro".

Faz-se necessário um exercício de leitura sobre os meios de comunicação com nossos alunos, junto a um trabalho de rememoração do passado, desconstruindo, decodificando o que parece dado, congelado e limitado pelos flashs exclusivos da $\mathrm{TV}^{4}$. A TV permitiu a todos nós ver, observar, sentir a guerra em Kosovo. Foi ela que nos fez ver o espetáculo da tecnologia da guerra, com seus fachos de luz, permeada pelos rostos angustiados dos refugiados, o que ajudou a construir a imagem de um inimigo e de um salvador prontos a sublimar nossas angústias. $\mathrm{O}$ olhar que tivemos através dela é um olhar sob procuração ${ }^{5}$, pois realizamos o mesmo caminho de quem manipulou a câmera, para escolher, priorizar, ler o real e até mesmo construí-lo como verdade.

Muitas vezes, na escola, não realizamos com os alunos um trabalho de leitura dessa construção, como, por exemplo, realizando a análise do movimento da câmera, suas paradas, sua prioridade; nem discutimos o critério para a seleção de pessoas a serem entrevistadas, o tipo de depoimento; o tempo em que eles permanecem no ar ou aparecem sendo analisados, depois, pelo apresentador. Até que ponto discutimos com nossos alunos as imagens de guerra, tornando claro o fato de que elas fazem parte de um cenário, onde as personagens assumem papéis através dos quais realizamos comparações e identificações com os nossos dramas diários?

\section{NEUTRALIDADE: \\ A ESCOLA USA O JORNAL}

É comum que os professores peçam aos alunos para que assistam ao telejornal ou leiam o jornal para "ficarem a par dos acontecimentos" e depois aceitarem os fatos e análises jornalísticas como verdades que não são questionadas como intenções de sujeitos nem são desconstruídas. Usar o jornal na escola aparece, assim, como uma grande inovação pedagógica, sem que o tratamento ou o método de análise dos meios de comunicação mude, reproduzindo-se os mesmos erros cometidos com o livro didático, por exemplo.

A suposta neutralidade da câmera ou do jornal é também aceita em sala de aula, trabalhando-se o resultado pronto, o dado. Não se analisam o movimento, a escolha ou o critério, nem o tempo ou o processo repleto de vida que estão por trás deles.

Em que momento discutimos com nossos alunos as imagens da guerra como signos, como cenários que também interferem em nossa forma de ver o mundo e, portanto, na produção do mundo em que vivemos? A escola parece se recusar a realizar o papel maçante mas necessário de ir contra a superficialidade, aprofundando discussões que estão dadas no

4. Afinal, este é o papel do historiador: trazer à tona, constantemente, o passado, os problemas não-resolvidos, as emoções nãocompartilhadas, a esperança não-realizada, como diria Walter Benjamin, o presente por si só não se explica.

5. O "olhar sob procuração" é uma expressão que nos permitimos apropriar de Arlindo Machado. 
dia-a-dia pelos meios de comunicação. Os educadores perdem-se, muitas vezes, na ansiedade de concorrer com eles e de serem tão divertidos e rápidos para dar ao aluno o show da aprendizagem. Esquecem-se de que, talvez, o interessante fosse justamente usá-los para estabelecer relações maiores, mostrando que eles não bastam para a compreensão do mundo. É preciso estabelecer elos e não ignorá-los ou querer disputar espaço com eles.

A aparente neutralidade da notícia é uma fabricação apresentada como signo da realidade, captada pelos repórteres, reforçada pelo distanciamento físico e cultural do espectador, ao mesmo tempo em que o encurtamento da distância pelas imagens ao vivo aproxima-a das emoções e da paisagem observada, tornandoas familiares.

A tecnologia tornou a guerra algo impessoal, pois mata-se a distância, atingindo-se alvos militares ou civis, e depois apresentando-se estatísticas, negociações, erros como se estivéssemos falando de um jogo. Por outro lado, a familiaridade provocada pelas imagens condiciona o entendimento e procura dar conta das angústias pessoais dos espectadores. Não é preciso pensar muito, pois os recortes dos noticiários dão a sensação de participação, de comunicação com os que sofrem.

Os alunos, motivados pelo que vêem na televisão, buscam informações nos sites da Internet, contatam vítimas da guerra, apresentando uma certa euforia de poder estar com alguém que vive o conflito, aproximando-se mais de sua dor. No entanto, não é apennas a dor que aproxima, mas também a emoção de estar lá. Alguns alunos, atraídos pelas imagens e pela narração de refugiados, chegam a afirmar: "Gostaria de estar lá!", "Essa guerra dever ser "da hora",

Como poderemos trabalhar esse misto de horror e fascínio se não discutirmos o processo que o produz?
Sabemos dos motivos da guerra, choramos e torcemos por um dos lados, julgamos os seres humanos envolvidos e apresentamos soluções óbvias para o problema, ou simplificamos tudo, baseados nas informações fragmentadas. Logo, saturados por tantas imagens, que em determinados momentos não nos chocam mais, torna-se normal $\mathrm{e}$ aceitável "jogar uma bomba e explodir aqueles loucos suicidas".

Tudo chega ao mesmo tempo, tornando difícil para nossos alunos - e para nós, tão próximos deles - enxergar o todo, selecionar, reduzindo nossa reação ao reflexo ou à inércia ou até mesmo à saturação. Muitas vezes as imagens servem também para aliviarmos nossas consciências, pois, afinal de contas, não há guerras no Brasil...

\section{REDUNDÂNCIA E BANALIZAÇÃO}

A notícia virou um grande espetáculo, o mundo, o palco, as pessoas, as personagens reais de um enredo codificado pela tela da televisão, e os cenários de morte nas guerras não trazem novidades, pois já foram vistos tantas vezes! O excesso de imagens e informações sobre a guerra provoca um estado de redundância que reduz o horror e torna banal o sentimento de indignação diante da morte.

É comum ouvirmos comentários sobre os bombardeios e a rapidez da destruição, a técnica, a eficiência militar, os erros e acertos ou até mesmo a emoção de estar lá, numa mistura de realidade e ficção dos filmes de guerra.

Como num filme ou num jogo, elegemos o bem e o mal, ou pior, passamos a admirar as estratégias, a inteligência e a esperteza do bem. O mundo da guerra passa a ser o mundo dos ditadores cruéis contra as vítimas eternamente perseguidas, e passamos a julgar e torcer por um dos lados. 
No caso de Kosovo, o presidente sérvio, Milosevic, foi apresentado constantemente como o carrasco nazista, assassino de centenas ou milhares de albaneses, através da realização da chamada limpeza étnica e da criação de campos de concentração. Descolado do tempo, o nazismo parece se repetir, fica mais fácil entender uma guerra como esta a partir de estereóti$\operatorname{pos}^{6}$, sem trabalhar a diversidade temporal, ignorada por alguns analistas.

Há poucas imagens que comprovem a alegação da OTAN sobre a limpeza étnica supostamente feita pelos sérvios. Não se trata aqui, naturalmente, de defender Milosevic, mas de discutir com nossos alunos o fato de que aquelas imagens reduzem-se a apresentar os campos de refugiados e sobre a possibilidade de inexistirem as que realmente comprovem o massacre de kosovares, o que deve colocar em discussão a ética dos meios de comunicação. Os telespectadores são convidados a se identificarem com as vítimas kosovares, reconhecendo nos sérvios os inimigos, os tiranos que não souberam respeitar os direitos, a cultura e a religião de seus companheiros de território. Diante dos constantes erros bélicos de suas forças e das perdas humanas decorrentes, a OTAN declara que "para combater o mal, é preciso ter sacrifícios", assim, justifica a morte de civis iugoslavos e os bombardeios sobre comboios de kosovares como necessários.

O processo histórico que culminou nesse grande e antigo conflito tem sido pouco abordado em sala de aula. Analisá-lo mais detidamente talvez permitisse, no mínimo, uma noção mais profunda do problema, sem reduzir os fatos de Kosovo a resultado da maldade ou do nazismo dos sérvios.

Os massacres, os estupros e a limpeza étnica parecem ser exclusivos dos sérvios, e não frutos de uma prática dos povos dos Bálcãs. Cruzamos muito pouco o processo histórico com esse presentismo da guerra. Questionamos minimamente as relações que permeiam os povos daquela região desde o século VII, dando como certo o direito de Kosovo à independência, sem considerar que, pelo direito internacional, a região pertence de fato à Sérvia, o que tiraria da OTAN o direito de nela interferir, sem passar pelo Conselho de Segurança da ONU e sem questionar os interesses dessa organização na guerra.

\section{PROFESSOR DIANTE DOS FATOS}

Não é o caso, aqui, de defender os interesses de um ou de outro lado, porque a guerra em si é fruto da violência praticada pelos lados envolvidos, mas falta ao professor posicionar-se, em relação aos fatos, selecionando e cruzando informações de outras fontes, distintas da televisão.

Discutimos com nossos alunos sobre outras guerras que também violam direitos humanos e nas quais não há interferência externa? Discutimos a conveniência da guerra? Discutimos se bombardeios são a solução para a violação dos direitos humanos?

A repetição exaustiva de cenas em que aparecem mortes e refugiados parece tornar a guerra inevitável e, portanto, aceitável. Afinal, é a democracia quem combate o mal. As armas teleguiadas parecem garantir que serão atingidos alvos, e não humanos, a não ser que haja erros.

Parece haver total transparência nas imagens e discursos da TV ou dos jornais sobre o que seja a guerra: o mal deve ser eliminado 
pela força, como num jogo de videogame. Em nome do combate à xenofobia, reforça-se $\mathrm{a}$ intolerância em relação aos inimigos ou a indiferença diante de seu sofrimento, justificadas pelo lado que tomamos.

A violência apresentada pelas imagens é constantemente reforçada sem que, em nenhum momento, se problematize a questão da guerra e a inserção do homem nela. As mortes são a repetição infinita ("sempre houve violência e sempre haverá") da história da humanidade. Há vidas diferenciadas: alguns merecem morrer, em nome da vida de outros, selecionados pela mídia como as vítimas.

Por que os Estados Unidos não optaram pela invasão terrestre da Iugoslávia? Há pesos diferenciados para as mortes de soldados da OTAN e de soldados sérvios e kosovares? Como lidamos com o tratamento dado à guerra pelos meios de comunicação? Até que ponto sabemos aproveitar a mídia para questionarmos com nossos alunos o processo que nos tornou tão indiferentes diante do horror ou

Resumo: A autora procura mostrar como as guerras, especialmente as atuais, como a de Kosovo, são apresentadas ao público pelos meios de comunicação. Analisa os recursos utilizados para envolver o espectador e levá-lo à armadilha do presentismo, expressão criada por Hobsbawn para designar o processo pelo qual imagens fragmentadas e repetitivas "formulam" a explicação dos problemas. Entrando no espaço educativo, critica a forma como esse processo é trabalhado em sala de aula, concluindo que, em lugar da participação virtual como se as imagens da guerra fossem um jogo de videogame, é necessária a identificação de sujeitos e intenções, e a compreensão do conjunto de relações sociais e políticas nas quais estamos inseridos, sendo informados e formados para também interferir e formar o mundo.

Palavras-chave: História, mídia, presentismo, espetáculo, guerra, sedução. admiradores da guerra e de suas estratégias? Trabalhamos o significado de um século permeado pela guerra e pelo tratamento da vida cada vez mais como algo inútil e supérfluo?

Por que não usar as cenas e notícias de guerra para questionar com nossos alunos por que nos acostumamos com a inevitabilidade da morte? Mais do que nossa participação virtual num jogo de guerra, precisamos identificar sujeitos e intenções, compreender o tecido de relações nas quais estamos inseridos, sendo informados e formados para interferir e formar o mundo.

É preciso, de forma urgente, que a escola saiba utilizar o conhecimento que constrói, não para negar, mas para saber dar, à carga de informações que recebemos diariamente pelos meios de comunicação, uma análise crítica e transformadora, trabalhando a tolerância, sem cair na indiferença, a pluralidade para não cair nos estereótipos, e a história grande tecido das relações humanas - para não cair no presentismo.

Abstract: The author shows how the wars, particularly the current ones, such as the war in Kosovo, are presented to the public by the means of communication. She analyzes the resources used to involve the spectator and to lead him to the "presentism" trap, an expression created by Hobsbawn to designate the process through which fragmented and repetitive images "formulate" explanations for the problems. Entering the educative space, she criticizes the way this process is worked in the class room, concluding that, instead of virtual participation as if the images of war were a videogame, it is necessary to identify subjects and intentions, and the understanding of the set of social and political relations in which we are inserted, being informed and formed also to interfere in and to form the world.

Key words: History, media, presentism, spectacle, war, seduction 